2 Stedman RL. The chemical comparison of tobacco and tobacco smoke. Chemical Reviews 1968;68:153-207.

3 Binder RE, Mitchell CA, Hosein HR, Bouhuys A. Importance of the indoor environment in air pollution exposure. Arch Environ Health 1976;31:277-9.

4 Lebowitz MD, Burrows B. Respiratory symptoms related to smoking habits of family adults. Chest 1976;69:48-50.

5 Colley JRT. Respiratory symptoms in children and parental smoking and phlegm production. $\mathrm{Br}$ Med f 1974;ii:201-4.

6 Bland M, Bewley BR, Pollard V, Banks MH. Effect of children's and parents' smoking on respiratory symptoms. Arch Dis Child 1978;53:100-5.

Weiss ST, Tager IB, Speizer FE, Rosner B. Persistent wheeze: its relationship to respiratory illness, cigarette smoking and level of pulmonary function in a population sample of children. Am Rev Respir Dis 1980;122:697-707.

8 Said G, Zalokar J, Lellouch J, Patois E. Parental smoking related to adenoidectomy and tonsillectomy in children. $f$ Epidemiol Community Health 1978;32:97-101.

9 Scholling RSF, Letai AD, Hui SL, Beck ST, Schoenberg JB, Bouhuys A. Lung function, respiratory disease, and smoking in families. Am f Epidemiol 1977;106:274-83.

10 Speizer FE, Ferris BJ, Bishop YMN, Spengler J. Respiratory disease rates and pulmonary function in children associated with $\mathrm{NO}_{2}$ exposure. Am Reo Respir $D$ is 1980;121:3-10.
11 Gortmacher SL, Walker DK, Jacobs RH, Ruch-Roiss H. Parental smoking and the risk of childhood asthma. Am $f$ Public Health 1982;72:574-9.

12 Pullan CR, Hey EN. Wheezing, asthma and pulmonary dysfunction 10 years after infection with respiratory syncytial virus in infancy. BrMed $\mathcal{F}$ 1982;284: 1665 -9.

13 Fergusson DM, Horwood LJ, Shannon FT, Taylor B. Parental smoking and lower respiratory illness in the first three years of life. 7 Epidemiol Community Health 1981;35: 180-4.

14 Colly JRT, Holland WW, Corkhill RT. Influence of passive smoking and parental phlegm on pneumonia and bronchitis in early childhood. Lancet 1974; ii: 1031 -4

5 Harlap S, Davies AM. Infant admissions to hospital and maternal smoking. Lancet 1974; ; :529-32. 16 Weiss ST, Tager IB, Schenker M, Speizer FE. The health effects of involuntary smoking. Am Re Respir Dis 1983;5:933-42

7 World Health Organisation. International classification of diseases. 9th revision, 1975 Vol 1. Geneva: WHO, 1977

18 US Department of Health and Human Services. The health consequences of smoking for women: report of the Surgeon General. Washington: US Government Printing Office, 1980.

19 Yue Chen, Wanxian Li. The effect of passive smoking on children's pulmonary function in Shanghai. Am 7 Public Health 1986;76:515-8.

(Accepted 7 April 1986)

\title{
Plasma cholesterol concentration and death from coronary heart disease: 10 year results of the Whitehall study
}

\author{
GEOFFREY ROSE, MARTIN SHIPLEY
}

\begin{abstract}
Ten year mortality from coronary heart disease in $\mathbf{1 7} \mathbf{7 1 8}$ middle aged men was related to their initial plasma cholesterol concentrations. The relative risk of death from coronary heart disease declined with age, but the absolute excess risk did not. The risk gradient was continuous over the whole range of cholesterol concentrations, the lowest mortality being among men with concentrations below the lowest decile. It seems that, as with blood pressure, the average cholesterol concentration in the population is too high: lowest concentrations are prognostically the best. A quarter of all deaths from coronary heart disease related to cholesterol occurred among men with concentrations above the top decile, but $55 \%$ occurred among men with concentrations in the middle three fifths of the distribution; this figure of $55 \%$ could be reduced only by a policy aimed at lowering concentrations in the whole population.
\end{abstract}

\section{Introduction}

The association between high blood cholesterol concentrations and a person's risk of coronary heart disease is now widely accepted. The relation at lower concentrations has been harder to assess, because the shallower gradient and lower incidence call for exceptionally large studies. The question is, however, of great importance in terms of the possible benefits of dietary advice to the population. In the Whitehall study plasma cholesterol concentration was measured in a large group of men whose mortality has now been followed up for over 10 years; this provided enough data for us to explore this question.

\section{Methods}

Data were available on 17718 male civil servants aged 40-64 in London. ${ }^{12}$ Plasma cholesterol concentration at entry to the study was measured on a capillary blood sample, using the then standard Technicon method N24a; it is now suspected that the readings may have been about $10 \%$ too low, and so the results are presented here within deciles or quintiles. The quintile points (uncorrected) were $4 \cdot 11,4 \cdot 75,5 \cdot 27$, and $6.05 \mathrm{mmol} / \mathrm{l}(159,184,204$, and 234 $\mathrm{mg} / 100 \mathrm{ml}$ ). Concentrations were not significantly related to age. Recording of deaths was virtually complete owing to the help of the National Health Service Central Registry. During the first 10 years 703 men died of coronary heart disease (International Classification of Diseases (eighth revision) codes 410-414)

\section{Results}

Table I shows mortality from coronary heart disease at 10 years within deciles and quintiles of plasma cholesterol concentration. There was a clear and highly significant trend over the whole range of concentrations, some small irregularities being well within sampling limits. The slope of the fitted linear regression corresponded to a change of 0.64 deaths from coronary heart disease $/ 100 \mathrm{men} / 10$ years for a change in cholesterol concentration of $1 \mathrm{mmol}(38.7 \mathrm{mg})$, with no significant departure from a linear trend. An optimal lower concentration could not be established: within the range observed the lower the concentration the better, as mortality associated with concentrations in the lowest tenth of the distribution was $9 \%$ lower than that associated with concentrations in the next lowest tenth.

If the mortality among all the men had been the same as that among the men whose concentrations were below the lowest decile then 482 rather than 703 deaths from coronary heart disease would have been expected, a reduction of $221(31 \%)$. This underestimates the true proportion of deaths from coronary heart disease attributable to cholesterol for two reasons. Firstly, it was not possible to establish the optimum plasma cholesterol concentration, relative to which the excess of deaths from coronary heart disease related to cholesterol could be measured, as the real "minimum risk" category seemed to be below that of the lowest tenth in the study. Secondly, as the cholesterol concentration was measured only once gradients at both extremes would have been underestimated because of the effects of random error and regression to the mean.

The final columns of table I show the best estimates of the distribution of the deaths attributable to cholesterol. Such deaths were spread over the whole range of cholesterol concentrations, with $55 \%$ arising in the middle of the distribution (between the first and fourth quintiles). Roughly one quarter were associated with concentrations above the top decile, and $43 \%$ with concentrations above the top quintile. The high proportion of attributable deaths at the top end of the distribution of concentrations was somewhat exaggerated because of the underestimate of total attributable 
TABLE I-Mortality from coronary heart disease (CHD) at 10 years according to initial plasma cholesterol concentration

\begin{tabular}{|c|c|c|c|c|c|}
\hline \multirow[b]{2}{*}{$\begin{array}{l}\text { Decile of } \\
\text { cholesterol }\end{array}$} & \multirow[b]{2}{*}{$\begin{array}{c}\text { No of } \\
\text { men }\end{array}$} & \multirow[b]{2}{*}{ \% Dead of CHD (SE) } & \multicolumn{3}{|c|}{ Attributable deaths } \\
\hline & & & No & $\%$ & \\
\hline$\leqslant 1$ & 1801 & $2.72(0.38)\} 2.85(0.29)$ & & & 2 \\
\hline $\begin{array}{l}-2 \\
-3\end{array}$ & $\begin{array}{l}1532 \\
2021\end{array}$ & $\begin{array}{l}3.00(0.44) \\
3.46(0.41)\end{array}$ & $\begin{array}{r}4 \\
15\end{array}$ & $\begin{array}{l}2) \\
71\end{array}$ & \\
\hline-4 & 1705 & $3.40(0.44)\} 3.44(0.30)$ & 12 & $5\}$ & 12 \\
\hline $\begin{array}{l}-5 \\
-6\end{array}$ & $\begin{array}{l}1708 \\
1686\end{array}$ & $\left.\begin{array}{l}3.45(0.44) \\
3.86(0.47)\end{array}\right\} 3.65(0.32)$ & $\begin{array}{l}13 \\
19\end{array}$ & $\left.\begin{array}{l}6 \\
9\end{array}\right\}$ & 14 \\
\hline-7 & 1848 & $3.95(0.45)$ & 23 & $10\}$ & 28 \\
\hline-8 & 1802 & $4.94(0.51)\}$ & 40 & $18\}$ & 28 \\
\hline-9 & 1825 & $4.77(0.50)\}_{5.37(0.37)}$ & 37 & $17)$ & 43 \\
\hline$>9$ & 1790 & $5.98(0.56)\}^{5.37(0.37)}$ & 58 & $26\}$ & 43 \\
\hline All & 17718 & $3.97(0.15)$ & 221 & 100 & 100 \\
\hline
\end{tabular}

*Deaths that would not have occurred if the mortality had been the same as that among men with cholesterol concentrations below the first decile.

TABLE II-Changes in relative and absolute risks of coronary heart disease with increase in cholesterol concentrations of $1 \mathrm{mmol} / \mathrm{l}(38.7 \mathrm{mg} / 100 \mathrm{ml})$ in different age groups

\begin{tabular}{lcc}
\hline Age $($ years $)$ & Odds ratio & Increased No of deaths/100/10 years \\
\hline $40-$ & 1.35 & 0.51 \\
$45-$ & 1.58 & 0.73 \\
$50-$ & 1.22 & 0.62 \\
$55-$ & 1.14 & 0.78 \\
$60-64$ & 1.18 & 1.29 \\
\hline$\chi^{2}(4 \mathrm{df})$ & 11.11 & 3.94 \\
$\mathrm{p}$ & $<0.05$ & $>0.3$ \\
\hline
\end{tabular}

cases (see above), but this exaggeration was balanced by the underestimation resulting from regression to the mean.

Analysis of the relation between mortality from coronary heart disease and cholesterol concentration by age (table II) showed that the relative increase in the risk of fatal coronary heart disease with rising cholesterol concentration got significantly less with advancing age but that the absolute increase in risk tended to get larger (though not significantly so), being $0.5 \% / 10$ years $/ \mathrm{mmol}$ cholesterol $/ \mathrm{l}$ in men aged $40-44$ and $1 \cdot 3 \% / 10$ years $/ \mathrm{mmol}$ cholesterol $/ \mathrm{l}$ in men aged 60-64.

The data in table I were used to estimate the relative potentials of two intervention policies. If men with cholesterol concentrations in the top fifth of the distribution were identified by screening and treated so that their mortality was reduced to that in men with concentrations in the next fifth (corresponding to a reduction in cholesterol concentration of about $18 \%$ ) then expected deaths at 10 years in this group would fall by $17 \%$ (from 194 to 160). This implies that for 1000 men screened and 200 treated roughly two deaths from coronary heart disease might be prevented over 10 years-that is, about $5 \%$ of the total deaths from coronary heart disease. If only the men with concentrations in the top tenth of the distribution were treated and their risk reduced to that of the men in the next tenth, the theoretical expected fall in total deaths from coronary heart disease would be $3 \%$. (In practice it would be much less, because of incomplete detection and compliance.)

A different approach would be to lower all cholesterol concentrations in the population. We estimate from our data that a reduction by the equivalent of one decile (about $8 \%$ ), with a corresponding fall in risk, would reduce deaths from coronary heart disease at 10 years by $8 \%$ (from about 40 to $36 / 1000$ population).

These theoretical benefits are underestimates because of the errors associated with using a single measurement of cholesterol concentration, but the relative potentials of the two policies can be compared with more confidence.

\section{Discussion}

Ideas of "normal" blood cholesterol concentrations date back to the laboratory practice of defining normality in terms of a range (for example, $\pm 2 \mathrm{SD}$ ) around the population average. This has led to the mistaken view that what is normal in the sense of common is also normal in the sense of good. Comparisons between populations, however, have shown remarkable shifts in the whole distribution of risk variables, ${ }^{3}$ so that a blood cholesterol concentration that might be regarded as low in Finland would be considered high in Japan. In the case of blood pressure it is now recognised that the risk of heart attack shows a graded relation over the whole range of values, subjects with pressures in the middle of the distribution having a greater risk than those with low pressures; as subjects with pressures in the middle of the range are so numerous, they in fact generate more cases than the less common subjects with hypertension. ${ }^{4}$

Recent evidence from the population screened in the American multiple risk factor intervention trial showed that in this respect there is a close analogy between blood pressure and serum cholesterol concentration. ${ }^{5}$ For the first time the number of subjects studied was adequate for the risk of coronary heart disease in subjects with cholesterol concentrations in the middle and lower parts of the range to be examined. From this five year follow up of 361000 men it became clear that at least $80 \%$ of the American population had too high a concentration in terms of their risk of a fatal heart attack. The same finding has now emerged from the Whitehall study. Thus, biologically speaking, few people in Western countries have a "normal" blood cholesterol concentration: the primary lipid problem underlying mass coronary heart disease should be seen as a population average that is too high, which then aggravates a secondary problem for those deviant individuals with hypercholesterolaemia.

The data from the Whitehall study permitted estimates of the potential benefits of various preventive approaches. The "high risk" strategy, exemplified by the Lipid Research Clinics programme, concentrates on detecting and treating those with concentrations in the upper segment of the distribution. ${ }^{6}$ Our data suggest that perhaps a quarter of the burden of coronary heart disease related to cholesterol in the United Kingdom arises in people with cholesterol concentrations above the top decile of the distribution, indicating that they are a potentially important target for control efforts. Regardless of whether or not such efforts are worth while for the individual people concerned, however, the benefit to the population as a whole turns out to be small.

The population approach to prevention seeks to lower the unacceptably high average cholesterol concentration in the population as a whole. The data reported here imply that the potential benefit of such a policy is substantially greater than that of the high risk strategy. Most of the benefit would be seen in people with concentrations in the top half of the distribution, but some benefit would probably be seen even in those with below average values.

Thus even a small decrease in the population's average cholesterol concentration could achieve much more than a policy of screening for and treating hypercholesterolaemia. Nevertheless, screening for hypercholesterolaemia can make some contribution, as well as being important for the subjects concerned.

\section{References}

1 Reid DD, Brett GZ, Hamilton PJS, Jarrett RJ, Keen H, Rose G. Cardiorespiratory disease and diabetes among middle-aged male civil servants. Lancet 1974; 1 :469-73.

Reid DD, Hamilton PIS, McCartney P, Rose G. Smoking and other risk factors for coronary heart disease in British civil servants. Lancet 1976;i:979-84.

3 Keys A, ed. Coronary heart disease in seven countries. New York: American Heart Association, 1970. (American Heart Association Monograph No 29.)

4 Rose G. Strategy of prevention: lessons from cardiovascular disease. Br Med f 1981;282:1847-51. 5 Neaton JD, Kuller LH, Wentworth D, Borhani NO. Total and cardiovascular mortality in relation to cigarette smoking, serum cholesterol concentration, and diastolic blood pressure among black and white males followed up for five years. Am Hean $\mathcal{J}$ 1984;108:759-70.

6 Lipid Research Clinics Programme. The Lipid Research Clinics coronary primary prevention trial results. Reduction in incidence of CHD. JAMA 1984;251:351-64.

(Accepled 3 fune 1986) 